\title{
BMJ Open Making headlines: an analysis of US government-funded cancer research mentioned in online media
}

\author{
Lauren A Maggio, ${ }^{1}$ Chelsea L Ratcliff, ${ }^{2}$ Melinda Krakow, ${ }^{3}$ Laura L Moorhead, ${ }^{4}$ \\ Asura Enkhbayar, ${ }^{5}$ Juan Pablo Alperin ${ }^{5}$
}

To cite: Maggio LA, Ratcliff CL, Krakow M, et al. Making headlines: an analysis of US government-funded cancer research mentioned in online media. BMJ Open 2019;9:e025783. doi:10.1136/ bmjopen-2018-025783

- Prepublication history for this paper is available online. To view these files, please visit the journal online (http://dx.doi. org/10.1136/bmjopen-2018025783).

Received 4 August 2018 Revised 21 November 2018 Accepted 23 November 2018

Check for updates

(c) Author(s) (or their employer(s)) 2019. Re-use permitted under CC BY-NC. No commercial re-use. See rights and permissions. Published by BMJ.

${ }^{1}$ Uniformed Services University of the Health Sciences, Bethesda, Maryland, USA 2University of Utah, Salt Lake City, Utah, USA

${ }^{3}$ National Cancer Institute, Rockville, Maryland, USA

${ }^{4}$ San Francisco State University, San Francisco, California, USA

${ }^{5}$ Simon Fraser University at Harbour Centre, Vancouver, British Columbia, Canada

Correspondence to

Dr Juan Pablo Alperin;

juan@alperin.ca

\section{ABSTRACT}

Objective To characterise how online media coverage of journal articles on cancer funded by the US government varies by cancer type and stage of the cancer control continuum and to compare the disease prevalence rates with the amount of funded research published for each cancer type and with the amount of media attention each receives.

Design A cross-sectional study.

Setting The United States.

Participants The subject of analysis was 11436 journal articles on cancer funded by the US government published in 2016. These articles were identified via PubMed and characterised as receiving online media attention based on data provided by Altmetric.

Results $16.8 \%(n=1925)$ of articles published on US government-funded research were covered in the media. Published journal articles addressed all common cancers. Frequency of journal articles differed substantially across the common cancers, with breast cancer $(n=1284)$, lung cancer $(n=630)$ and prostate cancer $(n=586)$ being the subject of the most journal articles. Roughly one-fifth to one-fourth of journal articles within each cancer category received online media attention. Media mentions were disproportionate to actual burden of each cancer type (ie, incidence and mortality), with breast cancer articles receiving the most media mentions. Scientific articles also covered the stages of the cancer continuum to varying degrees. Across the 13 most common cancer types, 4.4\% $(n=206)$ of articles focused on prevention and control, $11.7 \%(n=550)$ on diagnosis and $10.7 \%(n=502)$ on therapy.

Conclusions Findings revealed a mismatch between prevalent cancers and cancers highlighted in online media. Further, journal articles on cancer control and prevention received less media attention than other cancer continuum stages. Media mentions were not proportional to actual public cancer burden nor volume of scientific publications in each cancer category. Results highlight a need for continued research on the role of media, especially online media, in research dissemination.

\section{INTRODUCTION}

The US federal government is the largest funder of cancer research in the world. ${ }^{1}$ Thus, as a public good, it is imperative that the results from federally funded cancer

\section{Strengths and limitations of this study}

- Our findings provide funder groups a replicable method for future tracking of the characteristics of outputs from their research portfolio that appear in the online news media.

- We include a broad mix of online media organisations, such as traditional news media, broadcast organisations, trade publications, health and science news aggregators, and press release wire services and public relations platforms.

- The broad inclusion of online media organisations is critical as traditional news media are no longer the only sources, nor the primary sources, of health information for the public.

- The presented method includes only journal articles indexed in MEDLINE, which omits articles published in journals not indexed in that resource.

research be optimally disseminated to all stakeholders, including clinicians, funders, policy-makers and the public. The mass media play a key role in this dissemination. ${ }^{2-5}$ To this end, scientific journals have adopted media outreach strategies, such as the Journal of the National Cancer Institute's 'Memo to the Media', to facilitate research dissemination.

Media coverage is critical to health communication across the cancer continuum with particular influence on cancer perceptions and the preventive and screening behaviours among the public ${ }^{6-8}$ Yet little is known about the alignment between the characteristics of federally funded research articles and how they are covered in the media. This is especially true in light of the expanding nature of the digital media landscape. Such a lack of knowledge impedes the identification and mitigation of any potential discrepancies between the state of the research and what is depicted in the media. Additionally, it disadvantages the public because people may not be exposed to relevant research for making personal health decisions. 
In the USA, cancer is the most covered disease in the news ${ }^{9}$ and the public relies on this coverage as a key source of cancer information. ${ }^{1011}$ In turn, news reports of cancer research help shape public cancer beliefs, ${ }^{7812}$ subsequent prevention and detection behaviours ${ }^{13} 14$ and treatment preferences. ${ }^{4}$ Thus, a mismatch between media attention and available evidence can be problematic. For example, past content analyses found breast, blood and pancreatic cancers to be over-represented in the news relative to their actual prevalence, while male reproductive, lymphatic and thyroid cancers were under-represented relative to prevalence. ${ }^{515-17}$ Prevention and detection research also tended to receive less news coverage than other stages of the cancer continuum, such as cancer treatment. ${ }^{5817}$ While these prior media content analyses provide valuable information, they are based on older data, do not focus specifically on coverage of research and narrowly focus their analysis on selected mainstream news outlets. For example, researchers in 2010 analysed 13 mainstream print newspapers and magazines from 2005 to 2007, deciding to exclude online and niche news organisations. ${ }^{18}$ Thus, existing research fails to account for today's broad spectrum of online media that encompasses traditional online news sources as well as trade publications, health and science news aggregators, and press release wire services.

The current study aims to characterise and analyse cancer research articles funded by the US government, including those featured in a collection of more than 2000 online media sources. This analysis provides funders, scientists and policy-makers with an understanding of the dissemination of federally funded research via online media-information useful in future dissemination and funding initiatives. Additionally, this study provides a replicable method for tracking and analysing the outputs of funded research across a range of online media, which is critical as traditional news media are no longer the only sources, nor the primary sources, of health information for the public. ${ }^{19}$

\section{METHODS}

We conducted a cross-sectional study to examine journal articles on cancer funded by the US government and published in 2016 with the objectives of: (1) identifying, examining and characterising how the number of mentions of research in online news media varies by cancer type and stage of the cancer control continuum and (2) comparing the disease prevalence rates with the amount of funded research published for each cancer type and with the amount of media attention each receives.

To facilitate transparency and replication of our methods, we have made our computer code and the project's complete data set publicly accessible at https://doi. org/10.5281/ zenodo.1306985.

\section{Patient and public involvement}

Patients and the public were not involved in this study.

\section{Search strategy}

To locate articles, we searched PubMed on 1 March 2018, using the Entrez Programming Utilities ${ }^{20}$ with a query describing all documents published in journals (including editorials, letters to the editors, etc) about cancer published in 2016 with any identified source of funding (see table 1 for search details). We then extracted the record for each document including bibliographic data, funding information and Medical Subject Heading (MeSH) terms.

\section{Inclusion and exclusion criteria}

To meet our objective of identifying and characterising cancer articles that received media attention, we included journal articles on cancer funded by the US government that were published in 2016. We also specifically focused on articles that were described by National Library of Medicine indexers as being about the cancer types most frequently diagnosed in the USA, excluding non-melanoma skin cancers. These include cancers of the lung, colon and rectum, pancreas, breast, liver, prostate, leukaemia, non-Hodgkin's lymphoma, bladder, kidney, endometrium, melanoma and thyroid (in order of estimated deaths) ${ }^{21}$

Articles indexed with $\mathrm{MeSH}$ terms for a common cancer or a respective child term were counted as being about that particular cancer (eg, an article indexed with 'Leukemia, Plasma Cell' was counted toward the parent term 'Leukemia'). When terms for more than one cancer type were included in an article, we counted the article as an occurrence of each cancer. We categorised articles not described by at least one of these prevalent cancer types as 'other'. Due to a lack of standardised terminology for stages of the cancer continuum, we partitioned the

Table 1 PubMed search strategy for US government-funded research on cancer

Keywords neoplasm[mesh] OR "neoplasm metastasis"[mesh] OR cancer*[tiab] OR malign*[tiab] OR neoplas*[tiab] OR oncolo*[tiab] OR metasta*[tiab] OR tumor*[tiab] OR tumour*[tiab]

Funding "research support, american recovery and reinvestment act"[Publication Type] OR "research support, $\mathrm{n} i$ h, extramural"[Publication Type] OR "research support, n i h, intramural"[Publication Type] OR "research support, non u s gov't"[Publication Type] OR "research support, u s gov't, non p h s"[Publication Type] OR "research support, u s gov't, p h s"[Publication Type] OR "research support, u s government"[Publication Type]

Publication date "2016/01/01"[Date - Publication]: "2016/12/31"[Date - Publication] 
continuum into stages: prevention and control, diagnosis and treatment. We used corresponding MeSH qualifiers 'prevention and control', 'diagnosis' and 'therapy'.

After identifying relevant documents, we determined if they had received media attention by searching each document's PubMed identifier in the database from Altmetric LLC on 2 March 2018. For the purpose of this paper, we used Altmetric's definition of 'news media' sources, such that if either a link to a journal article or a phrase referencing a journal article was identified in any of the more than 2000 global media sources tracked by Altmetric, then it was considered a media mention. Altmetric tracks traditional news outlets such as the $B B C$ News, Los Angeles Times, New York Times and Washington Post, as well as newer, online-only sources such as The Daily Beast, Huffington Post and Vox. Additionally, the company tracks non-profit and governmental media organisations such as Kaiser Health News, Mayo Clinic and Voice of America, as well as niche news aggregators and portals such as BioMedReports, EurekAlert and Health Medicinet. Altmetric also tracks press release news wires such as BusinessWire and PR Newswire. In this study, we consider all these sources in our definition of 'media', and count every time Altmetric LLC finds a 'mention' of an article in one of these sources. (For a listing of media sources, see Altmetric. ${ }^{22}$ ) Of note, while Altmetric also tracks the attention research receives on social media, such as mentions in Facebook and Twitter posts, these forms of attention are outside the scope of this study.

\section{Statistical analysis}

Descriptive statistics were calculated to provide a baseline understanding of the frequency and proportions of journal article characteristics, as well as identify potential differences in the types of cancers and related stages of the cancer continuum covered. Subsequently, we examined the frequency and proportions of media mentions received by the articles. Analyses were conducted using SPSS V.21 and Microsoft Excel 365 ProPlus.

\section{RESULTS}

We identified 200264 articles in PubMed on cancer published in 2016. Of these, $11436(5.7 \%)$ reported a US government funding source (all subsequent analysis refers to this subset of $n=11436$, unless otherwise specified). The majority of US government-funded articles received funding from the National Institutes of Health (NIH; table 2) and many received a combination of funding from US government and non-US government sources, such that there were 19944 total funding sources across all articles.

Articles with multiple funding sources are counted once for each source.

All 13 common forms of cancer were the subject of at least one journal article (table 3). Overall, $41.0 \%(n=4687)$ of journal articles about cancer addressed at least one of these common types of cancer. Most journal articles
Table 2 Number of articles reporting each source of funding support

\begin{tabular}{lc}
\hline Funding source* $^{*}$ & $\begin{array}{l}\text { Number of } \\
\text { articles }\end{array}$ \\
\hline NIH Extramural & 10377 \\
NIH Intramural & 594 \\
American Recovery \& Reinvestment Act & 10 \\
US government Non-Public Health Services & 1922 \\
US government Public Health Services & 295 \\
Non-US government & 6746 \\
\hline
\end{tabular}

*Funding sources defined: https://www.nlm.nih.gov/pubs/techbull/ mj05/mj05_support_heading.html

addressed only one of the top 13 cancers ( $\mathrm{n}=4448), 195$ journal articles addressed 2 top cancers and 44 journal articles addressed 3-5 top cancers. Frequency of scientific articles differed substantially across the common cancers, with breast cancer $(n=1284)$, lung cancer $(n=630)$ and prostate cancer $(n=586)$ being the subject of the most publications (table 3; figure 1).

US government-funded articles were featured in 1483 unique scientific journals. Articles appeared most frequently in the journals Cancer Research ( $\mathrm{n}=292,2.6 \%)$, PLOS One $(\mathrm{n}=190,1.7 \%)$ and Proceedings of the National Academy of Sciences (PNAS) $(\mathrm{n}=179,1.6 \%)$. Overall, the 10 journals with the most US government-funded cancer research articles accounted for $14.2 \%$ of the total sample of articles (table 4).

Scientific articles also covered the stages of the cancer continuum to varying degrees (table 5 ; figure 2). Across the 13 most common cancer types, $4.4 \%(\mathrm{n}=206)$ of articles focused on prevention and control, $11.7 \% \quad(n=550)$ on diagnosis and $10.7 \%(\mathrm{n}=502)$ on therapy.

\section{Mentions in online media}

A total of $1925(16.8 \%)$ of cancer research articles were mentioned in online media at least once. The majority $(\mathrm{n}=9511,83.2 \%)$ of journal articles did not receive a media mention (median $=0$, mean $=1.84, \mathrm{SD}=11.98$, range $=0-462$ ). Of the 1925 articles that did receive at least one media mention, 735 received just one mention $(6.4 \%), 198$ received two mentions $(1.7 \%)$ and 992 $(8.8 \%)$ received three or more mentions. Four articles received over 300 mentions (table 6 ). ${ }^{23-32}$

The frequency of media mentions differed across cancer types (table 7; figure 3). The proportion of journal articles, by cancer type, receiving at least one media mention ranged from $7.0 \%$ of thyroid cancer articles to $24.8 \%$ of melanoma articles. Thus, while breast cancer had the largest total number of articles with one or more media mentions (251), melanoma articles received the largest relative proportion of coverage (24.8\%). In other words, while breast cancer research may have the widest reach in terms of absolute number of online media mentions, 
Table 3 Common cancer types covered by journal articles resulting from US government funds in relation to the number of estimated new cases in 2017 and estimated deaths ${ }^{21}$

\begin{tabular}{lccc}
\hline Cancer type & $\begin{array}{l}\text { No. of scientific articles } \\
\text { published in } \mathbf{2 0 1 6}(\mathbf{n}=\mathbf{4 9 8 4} \text { ) }\end{array}$ & $\begin{array}{l}\text { No. of estimated new } \\
\text { cases (rank) }\end{array}$ & $\begin{array}{l}\text { No. of estimated deaths } \\
\text { (rank) }\end{array}$ \\
\hline Breast & 1284 & $255190 \dagger(1)$ & $41070 \ddagger(4)$ \\
\hline Lung & 630 & $222500(2)$ & $155870(1)$ \\
\hline Prostate & 586 & $161360(3)$ & $26730(6)$ \\
Colon and rectal & 535 & $135430(4)$ & $50260(2)$ \\
Leukaemia & 544 & $62130(9)$ & $24500(7)$ \\
\hline Pancreatic & 309 & $53670(12)$ & $43090(3)$ \\
Liver & 302 & $40710(13)$ & $28920(5)$ \\
Melanoma & 302 & $87110(5)$ & $9730(12)$ \\
Non-Hodgkin's lymphoma & 170 & $72240(7)$ & $20140(8)$ \\
\hline Kidney & 106 & $63990(8)$ & $14400(10)$ \\
Endometrial & 77 & $61380(10)$ & $10920(11)$ \\
Thyroid & 71 & $56870(11)$ & $2010(13)$ \\
Urinary/bladder & 68 & $79030(6)$ & $16870(9)$ \\
\hline
\end{tabular}

*Articles may be counted multiple times if they include two or more cancers.

†Breast cancer total new cases 255190 (252710 females; 2470 males).

‡Breast cancer total estimated deaths 41070 (40610 females; 460 males).

a larger proportion of journal articles on melanoma are being mentioned online.

Media coverage also varied across cancer continuum stage for the top 13 cancers. While prevention and control articles received more relative coverage (32.0\%), compared with diagnosis $(20.0 \%)$ or treatment $(20.3 \%)$, this stage had fewer absolute mentions (66 mentions) compared with other stages (110 and 102 mentions, respectively), translating into lower absolute dissemination for the earliest stage of the continuum.

\section{DISCUSSION}

Media coverage is a key access point to cancer information for the public. ${ }^{10} 11$ In this study, approximately one out of every six articles reporting a US government funding source received media attention. For the public to receive useful information to guide health, it is imperative that the information disseminated to the public be accurately interpreted and aligned with available evidence. ${ }^{33}$ Our findings provide stakeholders with a valuable formative landscape of the current dissemination of federally funded cancer research captured across a spectrum of online media attention, including traditional news sources as well as trade publications, health and science news aggregators and press release wire services. Looking to the future, our approach provides funder groups, such as the National Cancer Institute (NCI) and NIH, with a replicable method for tracking

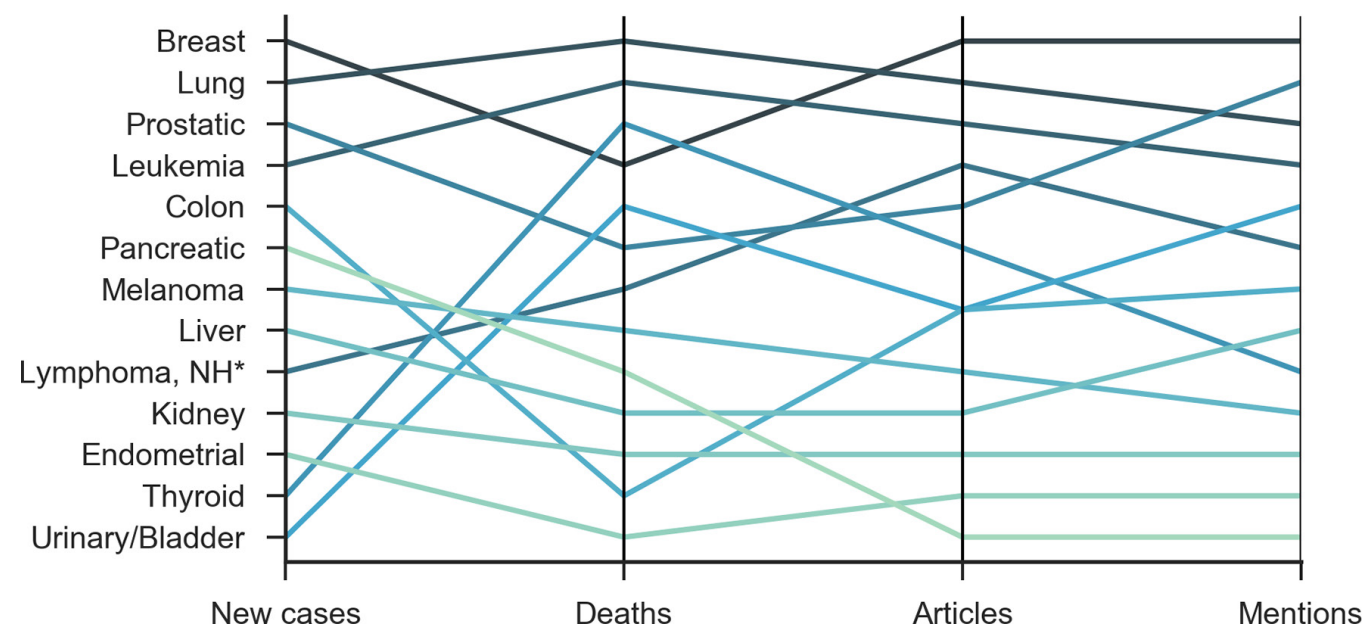

Figure 1 Common cancer types covered by journal articles resulting from US government funds in relation to the number of estimated new cases in 2017 and estimated deaths. ${ }^{21}{ }^{*} \mathrm{NH}$, non-Hodgkin. 
Table 4 Top 10 journals featuring the most US government-funded cancer research articles, with and without media coverage

Funded articles with Funded articles without Journal Total funded articles in media coverage ( $\%$ media coverage ( $\%$ of Cancer Research 2016 (\% of total articles) of articles in journal) articles in journal)

\begin{tabular}{llcrr}
\hline 1 & Cancer Research & $292(2.6)$ & $88(30.1)$ & $204(69.9)$ \\
2 & PLOS One & $190(1.7)$ & $20(10.5)$ & $170(89.5)$ \\
3 & $\begin{array}{l}\text { Proceedings of the National Academy of the } \\
\text { Sciences (PNAS) }\end{array}$ & $179(1.6)$ & $84(46.9)$ & $95(53.1)$ \\
4 & Oncotarget & $151(1.3)$ & $2(1.3)$ & $149(98.7)$ \\
5 & Blood & $149(1.3)$ & $40(26.8)$ & $109(73.2)$ \\
6 & The Journal of Biological Chemistry & $147(1.3)$ & $10(6.8)$ & $137(93.2)$ \\
7 & Scientific Reports & $145(1.3)$ & $25(17.2)$ & $120(82.8)$ \\
8 & $\begin{array}{l}\text { International Journal of Radiation Oncology, } \\
\text { Biology, Physics }\end{array}$ & $125(1.1)$ & $10(8.5)$ & $98(78.4)$ \\
9 & Breast Cancer Research and Treatment & $118(1.0)$ & $13(11.6)$ & $108(91.5)$ \\
10 & International Journal of Cancer & $112(1.0)$ & $99(88.4)$ \\
\hline
\end{tabular}

outputs from their research portfolio as they appear in online media.

While journal articles spanned all common cancer types, they were not represented in proportions mirroring estimates of cancer burden. Similar to earlier findings, breast cancer was the most-published-on cancer type, with more than double the frequency of the secondmost focused-on cancer, despite breast cancer causing fewer deaths than lung, colon and rectal, and pancreatic cancers. Prior research found a similar mismatch between the cancers prominent in the scientific literature and those with the highest actual burden (ie, prevalence, incidence or mortality). ${ }^{5}$ 15-17 This misalignment is noteworthy and the public, physicians, policy-makers and the media should understand that the research volume does not necessarily indicate the severity or population-level burden of the disease. It should also be noted that a complex set of factors, including investigator-initiated research proposals and available funding, influences scientific research.

Published articles disproportionately represented the stages of the cancer continuum, with prevention and control research accounting for a smaller proportion than diagnosis or treatment research. This echoes prior

Table 5 Scientific journal articles that identify a stage of cancer continuum

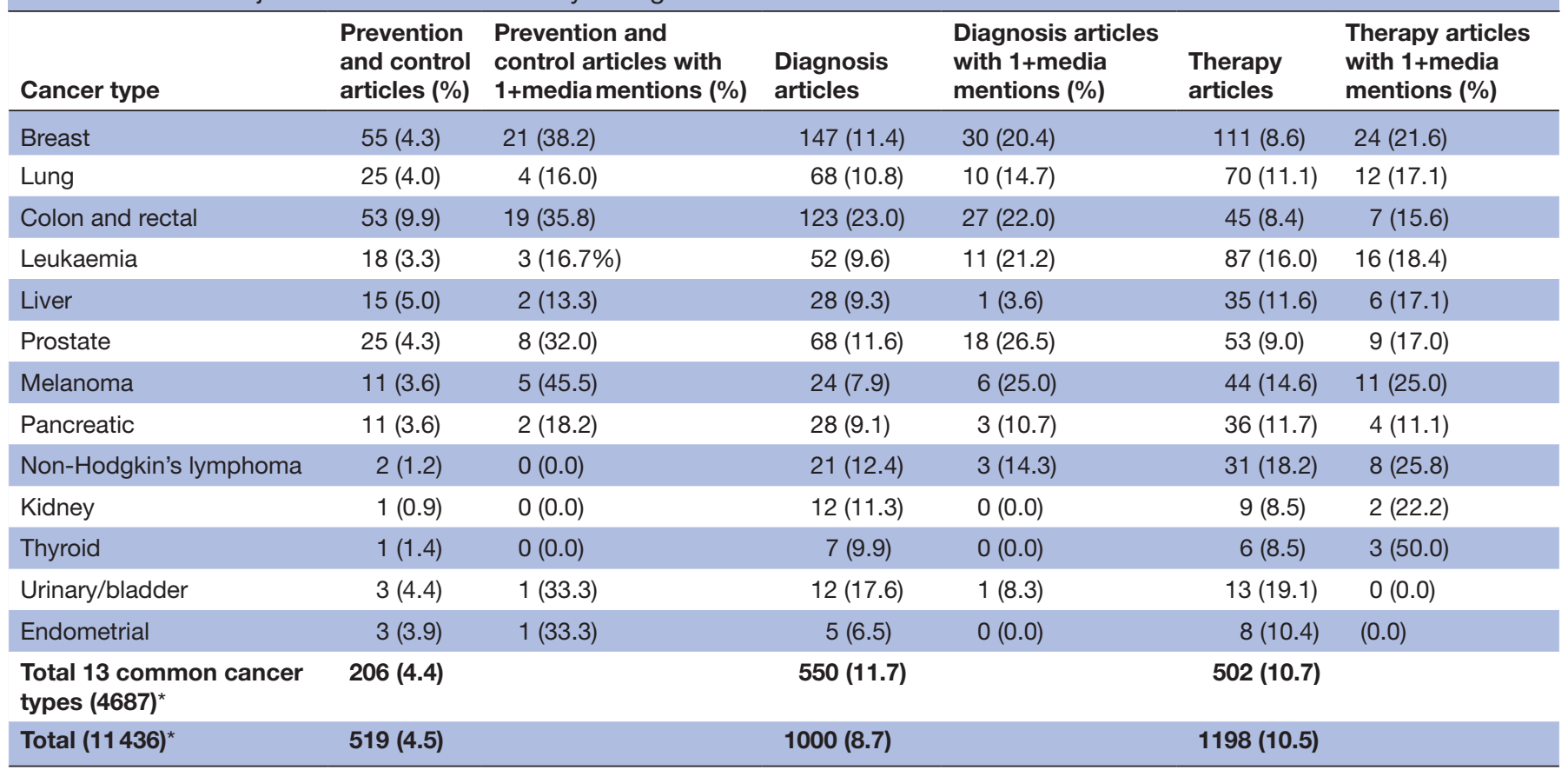

*Articles may address more than one stage in the cancer continuum. Therefore, these two totals do not reflect unique articles. 

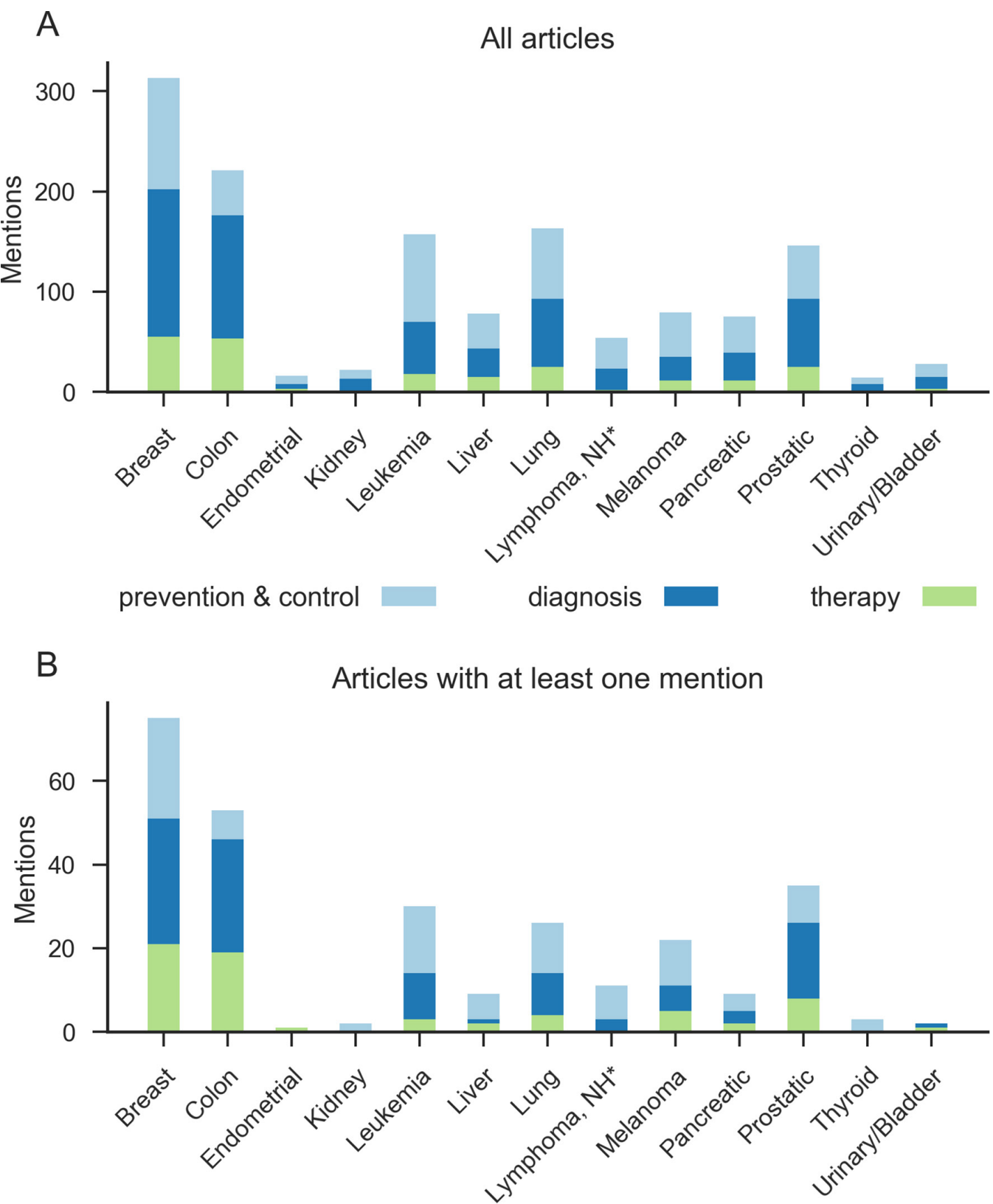

Figure 2 Articles indexed as addressing the prevention and control, diagnosis or therapy stages of the cancer continuum. Articles may address more than one stage in the cancer continuum. Therefore, these two totals do not reflect unique articles. ${ }^{\star} \mathrm{NH}$, non-Hodgkin.

research findings highlighting an under-representation of prevention-focused research. ${ }^{5} 817$ Notably, there were a number of cancers (eg, lung, melanoma) with a surprisingly low amount of prevention/control research represented in this sample.

Online media mentions were somewhat comparable across the 13 common cancers: around one-fifth to one-quarter of journal articles on each cancer type received media attention (with the exception of thyroid cancer, which was substantially lower). However, similar to publication volume, the volume of media mentions per cancer type was disproportionate to actual incidence of each cancer type and varied across the cancer continuum. Breast cancer was the most mentioned cancer type in online media, mirroring the higher volume of published scientific articles about breast cancer. This aligns with prior research that found certain cancers, including breast cancer, were over-represented in news coverage relative to incidence and mortality rates. ${ }^{5}$ Although fewer scientific articles on melanoma were published during this same period, melanoma research had the highest amount of relative media attention or per cent of articles receiving media mentions $(24.8 \%)$. We also found limited media attention to cancer prevention and detection research across the top 13 cancer types, consistent with past studies. ${ }^{5}{ }^{5}$

Due to the nature of our methods, we may have inadvertently excluded articles. For example, we included 
Table 6 Top 10 articles by media mentions

\begin{tabular}{|c|c|c|c|}
\hline Rank & Journal & Article title & $\begin{array}{l}\text { No of media } \\
\text { mentions }\end{array}$ \\
\hline 1 & Lancet & $\begin{array}{l}\text { Does physical activity attenuate, or even eliminate, the detrimental } \\
\text { association of sitting time with mortality? A harmonised meta-analysis of } \\
\text { data from more than } 1 \text { million men and women }{ }^{23}\end{array}$ & 462 \\
\hline 2 & Oncogene* $^{*}$ & $\begin{array}{l}\text { Targeting MET and AXL overcomes resistance to sunitinib therapy in renal } \\
\text { cell carcinoma }\end{array}$ & 355 \\
\hline 4 & JAMA & $\begin{array}{l}\text { Screening for Colorectal Cancer: US Preventive Services Task Force } \\
\text { Recommendation Statement }{ }^{26}\end{array}$ & 317 \\
\hline 5 & Science & Mutational signatures associated with tobacco smoking in human cancer ${ }^{27}$ & 244 \\
\hline 6 & Nature & Naturally occurring p16(Ink4a)-positive cells shorten healthy lifespan ${ }^{28}$ & 221 \\
\hline 9 & Science & $\begin{array}{l}\text { The phenotypic legacy of admixture between modern humans and } \\
\text { Neanderthals }{ }^{31}\end{array}$ & 178 \\
\hline 10 & JAMA Psychiatry & Association of religious service attendance with mortality among women ${ }^{32}$ & 176 \\
\hline
\end{tabular}

${ }^{*}$ Oncogene is a Nature journal.

only articles indexed in MEDLINE, which omits articles published in journals not indexed there. Additionally, authors or publishers may have failed to report funding sources; however, the NIH reports $89 \%$ compliance with the requirement to deposit manuscripts. ${ }^{34}$ In relation to content, we recognise that the US government also funds basic research that while in the future may greatly influence clinical cancer research, at this time would not be specifically indexed as cancer-related and therefore not retrieved. It is also possible that some articles related to cancer prevention/control (eg, topics such as tobacco cessation interventions) did not include relevant $\mathrm{MeSH}$ (eg, neoplasm) constituting our search criteria. Additionally, articles containing MeSH for more than one cancer type were included in counts across multiple categories, which may affect estimation. Media mention data were

Table 7 Number of scientific articles about common cancer types in relation to media mentions

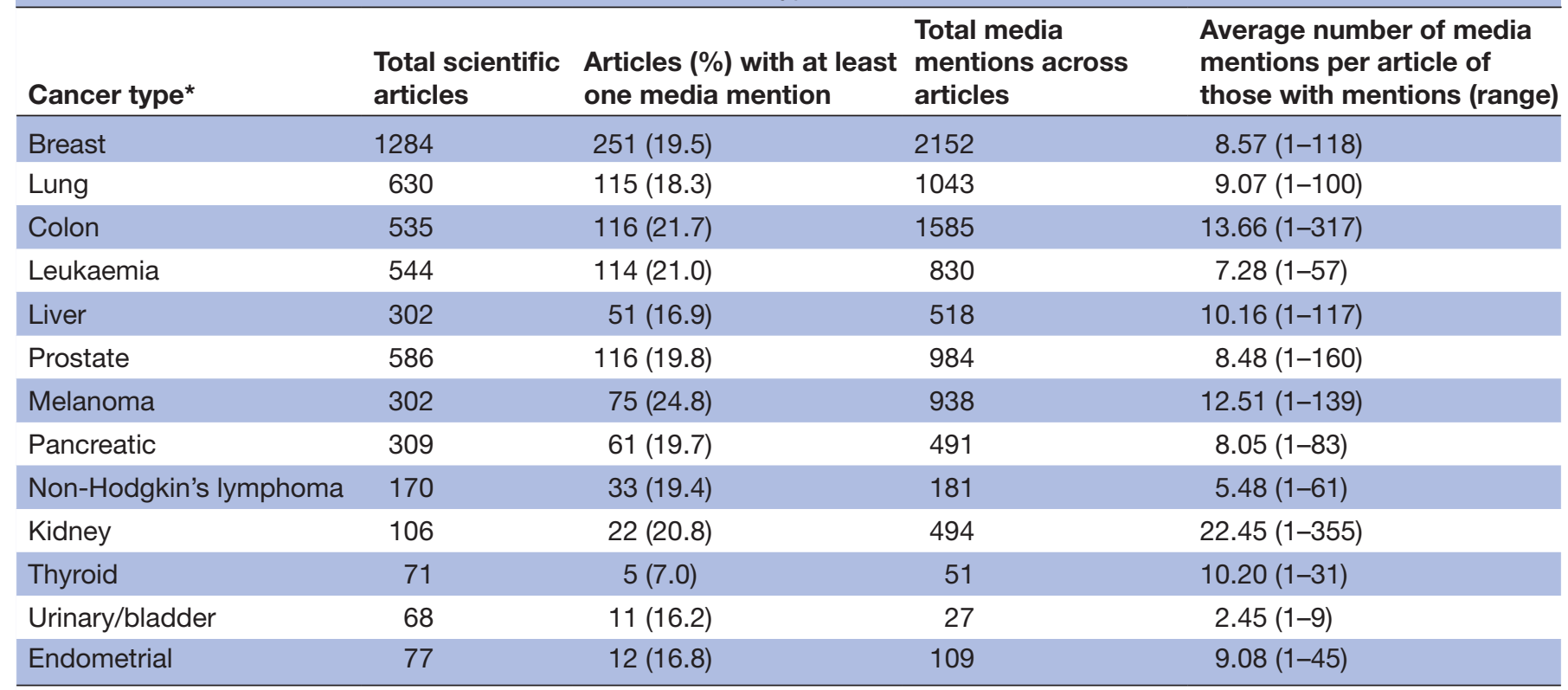

${ }^{\star}$ Articles can be included in more than one cancer type. 


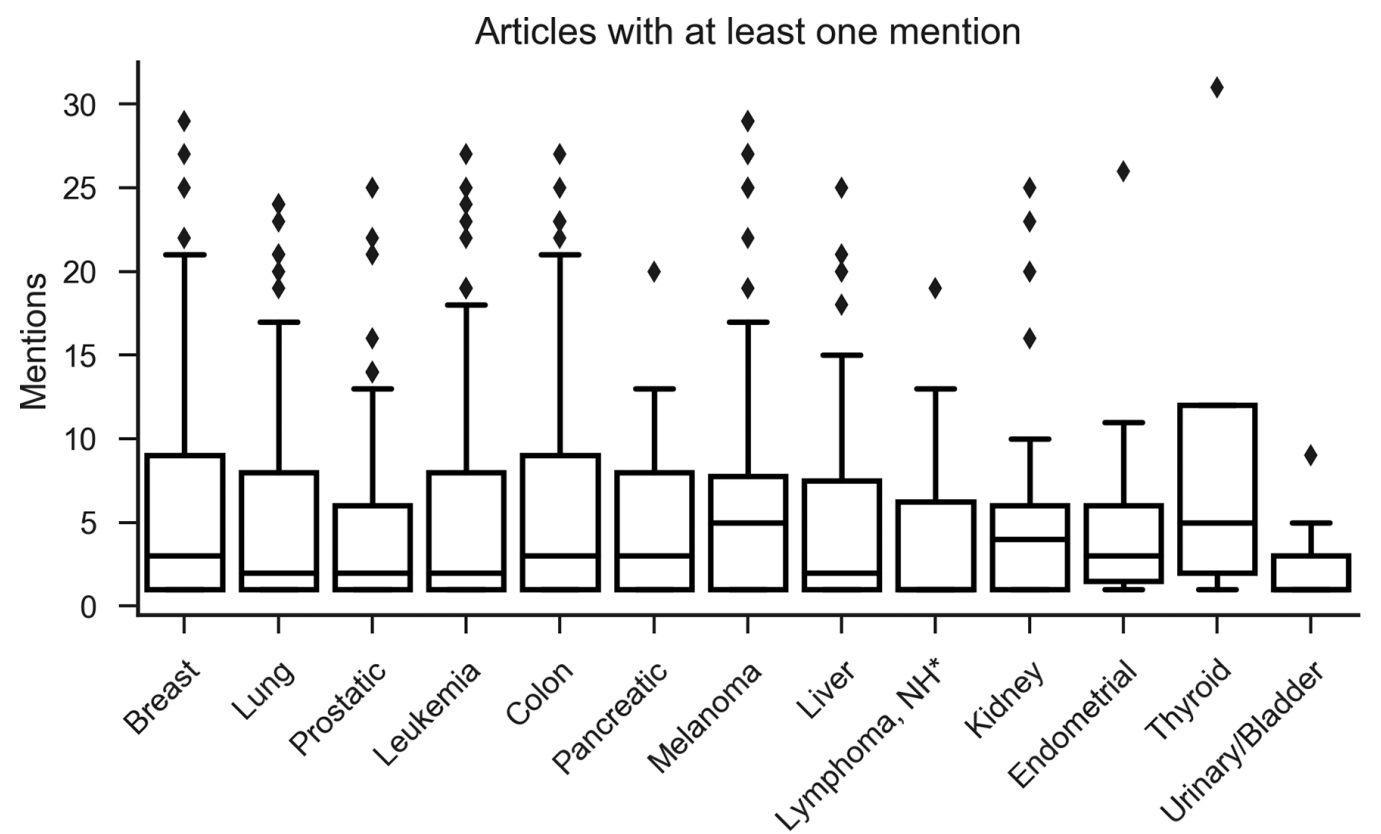

Figure 3 Articles with at least one news mention by cancer type. *NH, non-Hodgkin. ** Some outliers are not displayed in the figure as the $y$-axis was truncated at Q3 $+1.5{ }^{*} \mathrm{IQR}$.

collected by Altmetric, which searches online media for mentions of articles based on unique article IDs (eg, PubMed IDs), links to publisher websites and a series of proprietary techniques. Altmetric's approach, to our knowledge, offers the most comprehensive tracking of research in online media, but it remains imperfect, with some errors readily identifiable and an unknown number of missed mentions. Furthermore, while Altmetric searches over 2000 sources, other potentially important sources may not be included.

More broadly, while online media outlets are important channels for disseminating health information, we recognise there are other impactful channels, such as social media campaigns, that warrant study. ${ }^{3}$ Further, while we focused on the characteristics of scientific journal articles receiving media mentions, it is also important to consider how such research is covered and portrayed in the news media-notably online, where readership shows signs of growth-suggesting a future research opportunity.

Our findings provide a unique understanding of the dissemination of federally funded cancer research in online media via an extensive collection of media sources. This benchmark can be used to evaluate future dissemination and funding initiatives that take into consideration the new information landscape that reaches beyond traditional news media. Second, these results can inform scientists as to the characteristics of cancer research mentioned in the media. Third, these findings provide funder groups, such as the NCI and NIH, with a replicable method for future tracking of the outputs from their research portfolio that appear in the online news media.

Media mentions of research can impact the public's healthcare utilisation, physicians' practices and research funding agendas. ${ }^{35}$ For example, researchers credit a rapid decline in use of hormone replacement therapy by women and their physicians to the news media coverage of a randomised trial linking the therapy to potential harms. ${ }^{36}$ Additionally, media coverage can influence which research focus (eg, cancer types, cancer stages) is likely to receive federal funding, public policy attention or scholarly/scientific attention. A 2014 analysis found that discrepancies in media coverage and in public estimates of cancer were mirrored in federal funding for cancer research (eg, over-representation of breast and blood cancers and under-representation of bladder cancer, relative to actual incidence). ${ }^{7}$ ) This highlights an important area for future examination; data and methods from this study could facilitate such efforts.

Researchers have found that online media attention to scientific articles about cancer treatment correlates positively with the presence of media outreach. ${ }^{38} 39$ Thus, unsurprisingly the top 10 articles receiving the most media attention were published in journals that engage in outreach and dissemination activities. For example, four of the articles appear in the JAMA Network. The JAMA Network promises prospective authors a dedicated media team and formal press office that provides journalists early access to articles, writes press releases, and creates video and audio recordings of scientists discussing their findings. Similar services are provided by the Lancet, Science and Nature publishing groups, which account for all but one of the top 10 articles. Although we were unable to test the effect of such offices or services, because of a lack of a comprehensive list, the presence of papers among the most mentioned from publishers who are known to use them suggests an important role for targeted media outreach in ensuring that a broader range of scientific research receives online media 
coverage. Similarly, we were unable to test the individual media outreach practices that scientists, universities and scholarly societies may be employing, as this information is not captured systematically anywhere. Despite this limitation, we speculate that a need likely exists for more affordable outreach and dissemination services.

Media are recognised as an important channel for knowledge dissemination. ${ }^{3}$ However, online media generally have received little attention as a communication channel in science dissemination models and frameworks. Future research should examine how online media could be optimally incorporated into dissemination processes and knowledge translation strategies. Specifically, it will be useful to understand how marketing/communications teams can work with researchers to connect media more directly with emerging scientific research.

As a strength of this research, we included a broad mix of online media organisations, including traditional news media, broadcast organisations, trade publications, health and science news aggregators, and press release wire services and public relations platforms. This broad inclusion is critical as traditional news media are no longer the only sources, nor the primary sources, of health information for the public. ${ }^{19}$

Thus, our findings provide a unique understanding of dissemination of the results of federally funded cancer research in the broader landscape of online media. This benchmark can be used to evaluate future dissemination and funding initiatives that take into consideration the new information landscape that reaches far beyond traditional news media.

Contributors LAM, AE and JPA contributed to the conceptualization and design of the work, acquired and analysed the data, drafted the work and revised it critically for intellectual content, provided final approval of the version published, and agreed to be accountable for all aspects of the work in ensuring that questions related to the accuracy or integrity of any part of the work are appropriately investigated and resolved. CLR and LLM contributed to the conceptualisation and design of the work, drafted the work and revised it critically for intellectual content, provided final approval of the version published, and agreed to be accountable for all aspects of the work in ensuring that questions related to the accuracy or integrity of any part of the work are appropriately investigated and resolved. MK contributed to the conceptualisation and design of the work; analysed the data, drafted the work and revised it critically for intellectual content, provided final approval of the version published, and agreed to be accountable for all aspects of the work in ensuring that questions related to the accuracy or integrity of any part of the work are appropriately investigated and resolved.

Funding JPA and AE were funded by the Social Sciences and Humanities Research Council of Canada (SSHRC) — Insight Grant-No 435-2016-1029.

Disclaimer The views expressed in this article are those of the authors and do not necessarily reflect the official policy or position of the Uniformed Services University of the Health Sciences, the Department of Defense, the National Cancer Institute, or the US Government.

Competing interests None declared.

Patient consent for publication Not required.

Provenance and peer review Not commissioned; externally peer reviewed.

Data sharing statement To facilitate transparency and replication of our methods, we have made our computer code and the project's complete data set publicly accessible at: https://zenodo.org/record/1306985\#.WOCYqhJKh24.
Open access This is an open access article distributed in accordance with the Creative Commons Attribution Non Commercial (CC BY-NC 4.0) license, which permits others to distribute, remix, adapt, build upon this work non-commercially, and license their derivative works on different terms, provided the original work is properly cited, appropriate credit is given, any changes made indicated, and the use is non-commercial. See: http://creativecommons.org/licenses/by-nc/4.0/.

\section{REFERENCES}

1. National Cancer Institute. Overview and mission. https://www.cancer. gov/about-nci/overview (Accessed 15 Jun 2018).

2. Brodie M, Hamel EC, Altman DE, et al. Health news and the American public, 1996-2002. J Health Polit Policy Law 2003;28:927-50.

3. Brownson RC, Eyler AA, Harris JK, et al. Getting the word out: new approaches for disseminating public health science. J Public Health Manag Pract 2018;24:102-11.

4. Chen X, Siu LL. Impact of the media and the internet on oncology: survey of cancer patients and oncologists in Canada. J Clinical Onc 2001; 19:4291-7.

5. Slater MD, Long M, Bettinghaus EP, et al. News coverage of cancer in the United States: a national sample of newspapers, television, and magazines. J Health Commun 2008;13:523-37.

6. Institute of Medicine,. Committee on Health and Behavior and Board on Neuroscience and Behavioral Health. Health and Behavior: the interplay of biological, behavioral, and societal influences. Washington, DC: National Academy Press, 2001.

7. Jensen JD, Scherr CL, Brown N, et al. Public estimates of cancer frequency: cancer incidence perceptions mirror distorted media depictions. J Health Commun 2014;19:609-24.

8. Stryker JE, Moriarty CM, Jensen JD. Effects of newspaper coverage on public knowledge about modifiable cancer risks. Health Commun 2008;23:380-90.

9. Pew Internet \& American Life Project. Health online. http://www. pewinternet.org/2013/01/15/health-online-2013/ (Accessed 16 Jun 2018).

10. Kealey E, Berkman CS. The relationship between health information sources and mental models of cancer: findings from the 2005 Health Information National Trends Survey. J Health Commun 2010;15:236-51.

11. National Cancer Institute. Health Information National Trends Survey. https://hints.cancer.gov/ (Accessed 15 Jun 2018).

12. Niederdeppe J, Lee T, Robbins R, et al. Content and effects of news stories about uncertain cancer causes and preventive behaviors. Health Commun 2014;29:332-46.

13. Chapman S, McLeod K, Wakefield M, et al. Impact of news of celebrity illness on breast cancer screening: Kylie Minogue's breast cancer diagnosis. Medical J Aus 2005;183:247-50.

14. Yanovitzky I, Blitz CL. Effect of media coverage and physician advice on utilization of breast cancer screening by women 40 years and older. J Health Commun 2000:5:1117-34.

15. Hurley RJ, Riles JM, Sangalang A. Online cancer news: trends regarding article types, specific cancers, and the cancer continuum. Health Commun 2014;29:41-50.

16. Jensen JD, Moriarty CM, Hurley RJ, et al. Making sense of cancer news coverage trends: a comparison of three comprehensive content analyses. $J$ Health Commun 2010;15:136-51.

17. Stryker JE, Emmons KM, Viswanath K. Uncovering differences across the cancer control continuum: a comparison of ethnic and mainstream cancer newspaper stories. Prev Med 2007;44:20-5.

18. Fishman J, Ten Have T, Casarett D. Cancer and the media: how does the news report on treatment and outcomes? Arch Intern Med 2010;170:515-8.

19. Pew Foundation. Digital news fact sheet. http://www.journalism.org/ fact-sheet/digital-news/ (Accessed 15 Jun 2018).

20. Sayers E. E-utilities quick start. National center for biotechnology information. https://www.ncbi.nlm.nih.gov/books/NBK25500/ (Accessed 23 Feb 2018)

21. National Cancer Institute. Common Cancers. https://www.cancer. gov/types/common-cancers (Accessed 15 Jun 2018).

22. Altmetric. Sources of Attention. https://www.altmetric.com/aboutour-data/our-sources/news/ (Accessed 15 Jun 2018).

23. Ekelund U, Steene-Johannessen J, Brown WJ, et al. Does physical activity attenuate, or even eliminate, the detrimental association of sitting time with mortality? A harmonised meta-analysis of data from more than 1 million men and women. Lancet 2016;388:1302-10.

24. Zhou L, Liu XD, Sun M, et al. Targeting MET and AXL overcomes resistance to sunitinib therapy in renal cell carcinoma. Oncogene 2016;35:2687-97. 
25. Chiesa Fuxench ZC, Shin DB, Ogdie Beatty A, et al. The risk of cancer in patients with psoriasis: a population-based cohort study in the health improvement network. JAMA Dermatol 2016;152:282-90.

26. Bibbins-Domingo K, Grossman DC, Curry SJ, et al. Screening for colorectal cancer: us preventive services task force recommendation statement. JAMA 2016;315:2564-75.

27. Alexandrov LB, Ju YS, Haase K, et al. Mutational signatures associated with tobacco smoking in human cancer. Science 2016;354:618-22.

28. Baker DJ, Childs BG, Durik M, et al. Naturally occurring p16(Ink4a)positive cells shorten healthy lifespan. Nature 2016;530:184-9.

29. Ross S, Bossis A, Guss J, et al. Rapid and sustained symptom reduction following psilocybin treatment for anxiety and depression in patients with life-threatening cancer: a randomized controlled trial. J Psychopharmacol 2016;30:1165-80.

30. Dowell D, Haegerich TM, Chou R. CDC Guideline for prescribing opioids for chronic pain-United States, 2016. JAMA 2016;315:1624-45.

31. Simonti CN, Vernot B, Bastarache L, et al. The phenotypic legacy of admixture between modern humans and Neandertals. Science 2016;351:737-41.
32. VanderWeele TJ, Li S, Tsai AC, et al. Association between religious service attendance and lower suicide rates among US women. JAMA Psychiatry 2016;73:845-1.

33. Shenk D. Data smog: surviving the information glut: HarperCollins Publishers, 1997.

34. National Institutes of Health. Funding support. https://www.nlm.nih. gov/bsd/funding support.html (Accessed 15 Jun 2018).

35. Grilli R, Ramsay C, Minozzi S. Mass media interventions: effects on health services utilisation. Cochrane Database Syst Rev 2002:Cd000389.

36. Haas JS, Miglioretti DL, Geller B, et al. Average household exposure to newspaper coverage about the harmful effects of hormone therapy and population-based declines in hormone therapy use. $J$ Gen Intern Med 2007;22:68-73.

37. Schwartz LM, Woloshin S. The media matter: a call for straightforward medical reporting. Ann Intern Med 2004;140:226-8.

38. Haneef R, Ravaud P, Baron G, et al. Factors associated with online media attention to research: a cohort study of articles evaluating cancer treatments. Res Integr Peer Rev 2017;2:9.

39. Stryker JE. Reporting medical information: effects of press releases and newsworthiness on medical journal articles' visibility in the news media. Prev Med 2002;35:519-30. 